\title{
The generative affects of social media scroll-back interviews: In conversation with Spanish as a world language teachers during the COVID-19 lockdown in Australia
}

\begin{abstract}
The COVID-19 pandemic during 2020 resulted in researchers and teachers making the temporary and stressful shift to work remotely. While much research explores the 'how' of online teaching and learning, the affect of this on Spanish as a world language teachers (SWLTs) is underexplored. Working with SWLTs in Australia, I conducted social media scroll-back interviews amidst the COVID-19 lockdown in Australia. These interviews involved SWLTs screensharing, scrolling through their Facebook timelines and narrating posts related to the research topic. SWLTs highlighted the entanglement of COVID-19, pedagogy, policy, and politics through/with their Facebook timelines during the lockdown and the affect this generated in ways unique to SWLTs. Hence, this chapter aims to explore the potential for social media scroll-back method in emergency remote world language education (ER WLE) research and the generative affects of this. Using a diffractive reading to visibilise differences, I explore the nuanced material-discursive-social-political-digital entanglements in conversation with SWLTs asking: What are the generative affects of these entanglements and why do they matter? What emerged were unexpected examples of how this method interrupts traditional understandings of agency when research engages with alternative data such as wonder, hesitation and shame which I hope contributes to a (re)imagining of ER WLE.
\end{abstract}

\section{Highlights}

- Social media scroll-back method can work as a rapid rescoping method for research with world language educators during emergency remote teaching circumstances

- Incorporating social media into emergency remote teaching research with world language educators also invites alternative data beyond language/linguistics, thus, opening up the possibilities for exploring the personal/political/professional responses of world language educators to emergency remote teaching

- In conversation with Spanish as a world language teachers (SWLTs) during the COVID19 pandemic in Australia, social media scroll-back generated insights into the ways in 
which the technology and repositioning of participants as researcher could affect agency, hesitation, avoidance, and shame.

\section{In search of social media in emergency world language education research}

This chapter has emerged from the rapid rescoping of a project initially hoping to use action research to explore pedagogical approaches to response-able Spanish language practices in classrooms with Spanish as a world language teachers (SWLTs) in secondary schools in Queensland, Australia. The idea of response-able here refers to "the capacity to respond, response-ability" (Haraway, 2016, p. 78) and also acknowledges that "we are not all response-able in the same ways" (Haraway, 2016, p. 29). In March 2020, SWLTs', and my capacity to engage in action research was disrupted when a government mandate restricted research on school sites as teaching turned remote in response to the emergency circumstances of the COVID-19 pandemic. Thus, I turned my attention to rescoping the project by searching for a suitable method for working with SWLTs as part of emergency remote world language education (ER WLE) research; I began by exploring WLE methods more generally before digging into methods catering to emergency scenarios and finally, drilling down to the digital methods using social media that seemed most accessible at the time.

The search for method in WLE research is inherently complex given the interdisciplinary nature of the field. It is simultaneously entangled with both cognitive and social approaches from within and beyond the field (King et al., 2017). This is further complicated by debates about where to focus the data collection and analysis that guide the choice of method: at the macro or micro level? Yet the distinction between these the categories of macro and micro has been contested by Warriner (2012) who argue that these terms are not universally understood nor clear despite the presumption that macro approaches 
focus on broader societal issues and micro approaches on linguistic features (King et al., 2017). However, the recent sociolinguistic turn in WLE research acknowledges the need to develop methods which "bridge what is increasingly seen as a problematic and unproductive dichotomy between micro and macro" (King et al., 2017, p. xi). While much research has sought to attend to this call in recent years, the current context of COVID-19 in 2020 has highlighted the need to consider an additional layer of complexity in selecting method in WLE research: emergency and crisis situations that generate remote teaching responses. Here, remote teaching is broadly defined as methods of online and/or distance teaching and learning necessitated by emergency and crisis situations.

In the emerging field of emergency WLE, emergencies are defined as crisis circumstances (Hodges et al., 2020). While there is no singular or common definition of emergency in this context, a number of descriptions from the broader field of linguistics and education have emerged. One example surface from the field of crisis translation studies, in which crisis situations are extended beyond global pandemics. Drawing on the notion of “cascading disasters" from Pescaroli and Alexander (2015, p. 62), O' Brien and Federici (2019, p. 130) situate the notion of "crisis as a threatening condition with disasters as a triggering event of different magnitude and duration" in the linguistic arena. Looking at the UNESCO (2019) description of education in emergencies, there is further acknowledgement that pandemics, conflict, social unrest, and disasters caused by natural hazards warrant the need for emergency education. Additionally, the United Nations General Assembly Resolution (2010) on The right to education in emergency situations references additional emergency circumstances such as sexual violence, trafficking, and child labour; specifically in the Australian context, the Department of Foreign Affairs and Trade (2018) refers to emergencies situations as those arising from disasters including man-made disasters, drought, 
genocide and displacement. Taken together, these descriptions and definitions of emergency in the fields of linguistics and education point to a wide array of interconnected and complex factors that shape an emergency, suggesting that emergency WLE may take place in any one of these. What is less clear in the literature, however, is how (and if) researchers should and can approach WLE research in the midst of the aforementioned emergency circumstances. Given issues with access during such crises, digital means of research such as social media have become an increasingly popular avenue in WLE research.

Since the emergence of social media platforms over the past two decades, these platforms have continued to infiltrate users personal and professional lives. Social media users have increasingly turned to these platforms to make use of functions beyond the traditional social networking related to sharing photos, pictures and status updated. More recently, there has been a rise specifically in the use of social media for news sharing and fact-checking (Clayton et al., 2019; Dubois et al., 2020; Oeldorf-Hirsch et al., 2020), crisis communication (Maal \& Wilson-North, 2019; Malecki et al., 2020; Xie et al., 2017; Xu, 2020) as well as a range of teaching and learning activities (Carpenter \& Harvey, 2020; Manca, 2020; Xue \& Churchill, 2020). Moreover, according to Statista (2020) there are currently 2.7 billion monthly users on Facebook. As a result, world language researchers have begun to question the possibilities social media in particular might hold as not only a source of data but also as a space/place for method.

Existing studies incorporating social media as method in world language research tend to frame social media as a source of data without specifically referencing its role as method. Commonly, studies have explored learner attitudes towards various social media sites using such as Facebook (Sirivedin et al., 2018), Twitter (Taskiran et al., 2018), as well as YouTube and Google+ (Villafuerte \& Romero, 2017) using questionnaires. Social network Heınrıcns, ע. H. (८U८I) I ne generatıve errects оr socıaı meaıa scrolı-Dack Intervıews: In conversatıon witn spanısn as a world language educators during COVID-19 in Australia. In J. Chen (Ed.), Emergency remote teaching. Springer. 
analyses (SNA) of social media sites (in combination with surveys) have been conducted in a number of studies in attempts to map the complex social relationships that shape learning in the context of online networks. To illustrate, this approach has been applied to better understand peer-to-peer interactions (Peeters, 2019), or learners' grammatical accuracy (Paul \& Friginal, 2019). Studies have also focused on the potential for social media sites in the development of learners' foreign language literacy skills through interactions with native speakers via thematic analysis of hashtags on Twitter (Solmaz, 2017). Whilst these studies have primarily been concerned with learners, other studies exploring the interaction of world language educators and social media generally explore professional development and reflective practice. The role of social media sites for building communities of practice and staying in touch after professional development sessions or as a form of engaging with the field on a regular basis for world language educators has also been explored (Carpenter \& Krutka, 2015). For instance, reflective practice through the implementation of social media tools in WLE has been explored using traditional case study methodology (Xue \& Churchill, 2020); however, the more recent poststructural/critical turn in world language research has also seen a keen interest in exploratory methods such as critical autoethnography combined with social media emerge. As one example, Kasparek and Turner (2020) incorporate Facebook messenger communication as part of reflective practice in a duoethnographic approach. Seemingly absent from these studies are suggestions for how to approach WLE research in times of crisis when additional ethical considerations around social distancing, the burden of participation, and access to participants must be taking into further consideration. Addressing response-able languaging is of particular relevance for SWLTs given the increasing demand for Spanish language skills worldwide combined with the underlying ethical issues associated with teaching and learning a colonial language in another colonial context (Heinrichs, 2020).

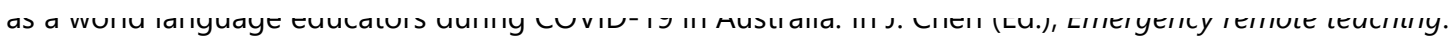
Springer. 
In this chapter, I propose a method for ER WLE research in an attempt to address some of the underlying restraints and situated ethical considerations for this context. In doing so, I explore social media scroll-back interviews through a diffractive reading highlighting the affects this method generates in a project exploring response-able Spanish languaging practices. In this paper, the term response-able refers to "the capacity to respond" (Haraway, 2016) in contrast to typical understandings of responsible as “morally responsible for one's behaviour" (Oxford Dictionary, 2021). It also is worth noting here that the understanding of affect I refer to moves beyond psychologised affect as specific feelings or emotions including motivation, grit, anxiety or confidence as commonly referred to in existing studies on online language education and language studies (Arnold, 2019; Besnier, 1990; Lee \& Chen Hsieh, 2019; Reinders \& Wattana, 2014; Tananuraksakul, 2015). Instead, I refer to a turn to affect in research which envisages a much broader notion of affect as the performative, bodily, personal encounters emerging from intra-actions of material-discursive, human and morethan-human (Ahmed, 2014; Haraway, 2016; Riley, 2005). Such a turn remains open to emotions and feelings although also invites examples such as fear, shame, disgust as entangled with embodied reactions/responses with agency and the more-than-human including technology. Hence, this approach serves the dual purpose of showcasing how social media data can diffract traditional discourse-based data and uncover the underexplored affective responses of SWLTs as an example of more ethico-onto-epistemological (Barad as cited in, Heinrichs, 2020) research during times of crisis.

\section{Why social media in ER WLE research now?}

More than just easing loneliness, such digital tools offer affordances for education in an emergency. As many K-12 schools rapidly transition to remote online forms of teaching and learning, further distancing students from classmates, friends, teachers 
and public life, social media offer benefits (Greenhow \& Chapman, 2020, p. 342)

Approximately $80 \%$ of Australians between 16-64 years of age access Facebook on a monthly basis with those most likely to do so being females between 25-44 years of age (Hootsuite, 2020) who also constitute the largest cohort of WLEs in Australia (Weldon et al., 2014). Furthermore, use of social media such as Facebook has been shown to peak during crisis akin to the 2020 COVID-19 pandemic resulting in its use to engage students in civic participation and community building particularly of students engaged in remote education (Greenhow \& Chapman, 2020). Given the additional complexities of misinformation or 'fake news' during crises, the aforementioned skills seem particularly important. However, the responses of WLEs is largely ignored, possibly due to the perception that the informal language use and content on social media is not appropriate in educational spaces (Galvin \& Greenhow, 2020). Research with social media such as Facebook seems even more relevant given the practical restraints on WLE researcher in 2020. This chapter outlines a project that took place during the first half of 2020 during the COVID-19 pandemic in Australia. This meant that while there were a number of activities I was interested in incorporating into the project, those available to me and those I was capable of responding to were situated in the unique circumstances of government lockdowns, social distancing laws and, as of March 31st, a mandate from the Queensland Department of Education that research "in state schools or other educational sites be postponed until further notice" (Queensland Government, 2020). The ease of accessibility of social media, therefore, provides an advantage in this situation.

These unique circumstances led me to wonder, if the context of remote education during COVID-19 was increasing the engagement of our largest cohort of WLEs with Facebook, and we are aware of the potential for this social media networking site to foster 
civic participation and community building, what might ER WLE research that taps into this look like? What kind of methods(ology/ies) might help ER WLE research address this? And in what ways might WL educators respond to ER WLE research with social media? These questions and concerns have guided the project beginning with a consideration of what this project might look like what using diffracting as theory and allow me to continue exploring response-able Spanish languaging practices.

\section{A guiding light: Diffracting data with theory}

Like the diffraction patterns illuminating the indefinite nature of boundariesdisplaying shadows in 'light' regions and bright spots in 'dark' regions — the relation of the social and the scientific is a relation of 'exteriority within' (Barad, 2003, p. 803).

The above description of diffraction has guided my research in this project about response-able Spanish languaging practices and attempts to address my research questions here asking: What kind of methods(ology/ies) might help ER WLE research address the unique circumstances of COVID-19? An admittedly complex concept developed by feminist philosophers Donna Haraway and Karen Barad with backgrounds in primatology and quantum physics respectively, it may seem an unlikely companion in ER WLE research. Yet I saw the relation between the social and the scientific increasingly important for exploring the personal/professional lives of SWLTs during COVID-19 especially, so that I could avoid getting stuck in positivist approaches which sought to uncover patterns of sameness in data and were wary of differences. Hence, I found solace in Karen Barad (2007) and Donna Haraway’s (2016) work on diffraction which encourages thinking about "patterns of difference and their entanglements with matter and meaning" (Barad, 2007, p. 29) and the "effects of these differences" (Haraway, 2016, p. 90). In other words, diffraction, as opposed 
to reflection/reflexivity which focuses on sameness and correction, attempts to map the interferences of multiple differences (Barad, 2007), but in doing so requires different ways of doing ER WLE research and different ways of thinking about what counts as valid ER WLE research data. For these reasons, this concept supports work that is open to more "inventive provocations" (Dolphijn \& Tuin, 2012, p. 50) and transdisciplinary rather than interdisciplinary inquiry (Bozalek \& Zembylas, 2017). This could include WLE from different language working together or with those from other disciplines and looking beyond what is traditionally considered linguistic data.

Furthermore, allowing myself to be guided by the concept of diffraction has forced me to question "what counts as 'data"” (Benozzo \& Gherardi, 2019, p. 45) and focus less on "what is and more on...what might be and what is coming into being" (St. Pierre, 2019b, p. 4). Although it is impossible to name and list the specific types of alternative data that might emerge when guided by the concept of diffracting, I have found it helpful to refer to the prior research for inspiration and examples. Some of the earliest work in this regard relates to what St. Pierre (1997) to as "transgressive data"; she identifies these are: emotional data, dream data, sensual data and response data and explains how they are out-of-category in that they move beyond words and/or language. Further, transgressive data challenge the notion that data require words to be interpreted by looking for those data which escape language (St. Pierre, 1997).

More recently, scholars have added further suggestions to the pool of potential alternative data with similarly, more-than-language qualities. Benozzo and Gherardi (2019) conceptualise 'not-yet' data as those which appears in the shadows of research and may be described as illegible, wonderous, disorienting, hesitant and worn out. Mayes and Wolfe (2018) introduce shame-interest whereby educational researchers embrace their interest in shameful and/or shame inducing research as potential avenue for ethical research practice. Heinrichs, D. H. (2021) The generative effects of social media scroll-back interviews: In conversation with Spanish as a world language educators during COVID-19 in Australia. In J. Chen (Ed.), Emergency remote teaching. Springer. 
This ties in with the affective turn in data promoted by feminist scholars such as Sara Ahmed (2004) which is continually being re-imagined in various disciplines as everything from affective trouble (contradiction, disattachment, blame) in studies of social semiotics (Gafter \& Milani, 2020) to embodied affect in gender studies (fear, loss, hope) (Fullagar \& Pavlidis, 2020). I also see the discussion by Lupton et al. (2018) about the ways in which senses, space, affect, and affordances contextualise personal data generated by digital devices interact as useful for the ways in which personal data could potentially entangle emotion, affect and social media in ER WLE research. Considering the potential for diffraction to expose alternative data, I then needed a method for doing so that also took the lockdown context into consideration and provided opportunities for more-than-language data to emerge.

\section{Diffracting method: social media scroll-back interviews}

I started by thinking over the methods I had come across while studying, attending conferences and in my reading. Initially, I considered simply conducting online interviews via Zoom. Yet the more I considered this, the more I came to see how this method may not dig into the personal and professional examples of response-able Spanish languaging practices I hoped to explore. At this point, I thought back to December 2019, where at the Cultural Studies Association of Australasia Conference, a colleague suggested we attend a panel in which one of the presenters would be describing her Honours project using an innovative approach we had never heard of before: scroll-back method. We came to learn that scroll-back method was exactly what it sounded like: "a qualitative research method that works within interviews whereby a researcher and participant 'scroll back' through the social media history of the participant” (Robards \& Lincoln, 2019, p. 1). Initially, I was unconvinced by the simplicity of scroll-back method; however, after seeing the Honours student present, where she combined the method with Instagram posts and new material Heinrichs, D. H. (2021) The generative effects of social media scroll-back interviews: In conversation with Spanish as a world language educators during COVID-19 in Australia. In J. Chen (Ed.), Emergency remote teaching. Springer. 
theory in complex, innovate and provocative ways to explore relationality with/to social media, I was interested in exploring the potential ways that scroll-back method could highlight different data in my project (Kamberelis et al., 2018). However, it wasn't until March 2020 amidst the looming lock-down in Australia due to COVID-19, I became increasingly aware that I might need a suitable rapid research method given the emergency health situation for my project exploring response-able Spanish languaging practices from the perspective of SWLTs. Thus, the simplicity of social media scroll-back method became one its greatest strengths in this context. This was largely due to the method requiring very little training, being easily accessible from geographically diverse locations and a source of longitudinal and trans-semioticizing data as described by Wu and Lin (2019, p. 253) as "language as entangled with many other semiotics (e.g. visuals, gestures, bodily movement) in meaning-making...intimate multi-verbal/multimodal/multisensory entanglement”. At this point, I incorporated scroll-back method into my project through nine separate one-on-one interviews via Zoom during which SWLTs shared their screens and paused to narrate any posts related to response-able Spanish languaging practices. On average the interviews lasted 90 minutes, thus, we scrolled past innumerable posts. Therefore, for practical reasons, the number of posts was not tracked.

Although Robards and Lincoln (2019) outline a series of steps which can be followed to conduct scroll-back method interviews, I used their advice as a guide and began by contacting SWLTs through a language teachers' Facebook group as this ensured anyone I was interested in working with would have a Facebook account and would be able to take part in a one-on-one interview using this. After reaching out to SWLTs through the Facebook group, a number expressed interest in the one-on-one interviews but also concern that they did not have what I was looking for on their Facebook timeline, namely because they did not think they used Spanish on their timelines. They later explained that this was due Heinrichs, D. H. (2021) The generative effects of social media scroll-back interviews: In conversation with Spanish as a world language educators during COVID-19 in Australia. In J. Chen (Ed.), Emergency remote teaching. Springer. 
to living in Australia, or for many, because it was not their first language and many of their Facebook friends didn't understand Spanish, so they didn't want to alienate anyone; although one SWLT, Alejandro ${ }^{1}$, proudly exclaimed, “it usually doesn't bother me if I'm posting in another language and it's like, yeah, if they can translate it or if it comes up translated then that's fine but if they - if it doesn't, too bad, yeah, too bad, that's so sad". However, mostly, it took some explanation to ensure SWLTs who were interested understood that I was not hoping to see only Spanish, but rather I was hoping for SWLTs to narrate examples of response-able Spanish languaging practice as they appeared on their Facebook timelines. These examples did not have to use Spanish and examples beyond their Facebook timelines were also welcomed. Additionally, SWLTs could choose to focus on posts related to language teaching, different uses of language or school related responsibilities, this was not explicitly the focus. Instead, I left it up to the SWLTs to decide which posts contained content of relevant to response-able Spanish languaging although I also asked them to stop on posts I considered relevant. Figure 1 highlights examples from my own Facebook timeline of the types of posts that could be narrated including some related to alternative types of language usage such as translanguaging (using multiple linguistic and semiotic features (García \&

Figure 1 Examples of response-able Spanish languaging from Facebook timeline

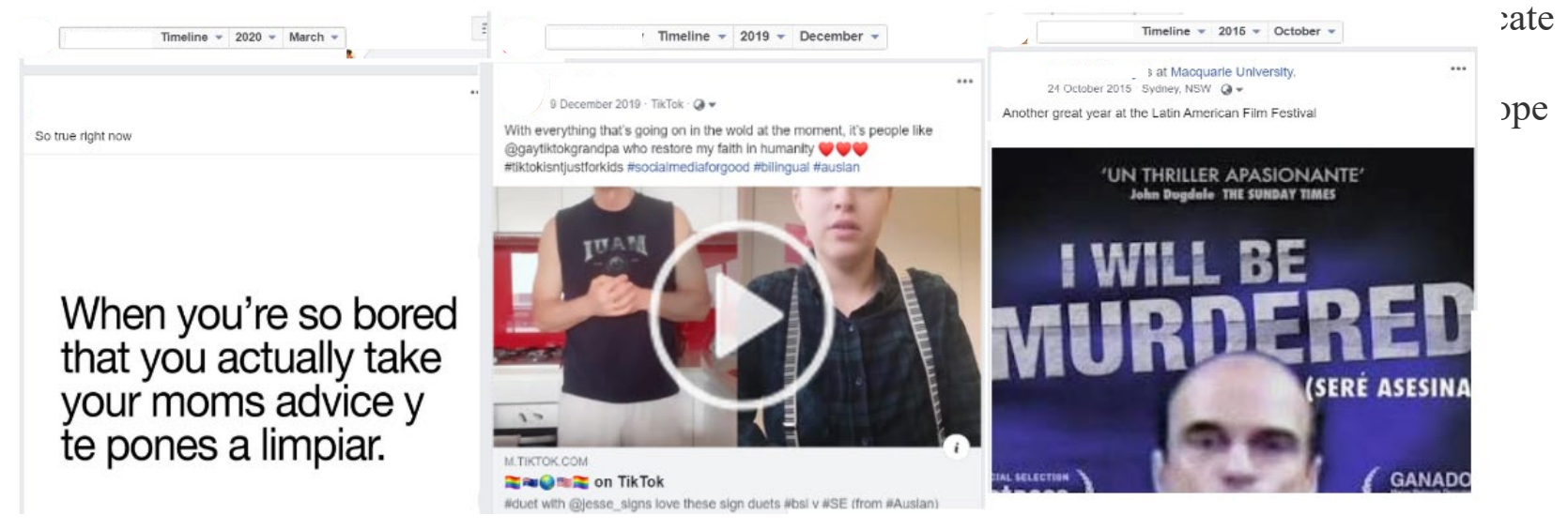

\footnotetext{
${ }^{1}$ All names of SWLTs in this chapter are pseudonyms Heinrichs, D. H. (2021) The generative effects of social media scroll-back interviews: In conversation with Spanish as a world language educators during COVID-19 in Australia. In J. Chen (Ed.), Emergency remote teaching. Springer.
} 
After convincing nine SWLTs that their timeline posts would be suitable, I was able to organize a time outside of school hours to have the one-on-one interviews using Zoom from the comfort of their homes. Given my interest in SWLT's conceptions of response-able languaging practices, the demographic data was of less interest. However, for those interested, I spoke with 9 teachers across Queensland, New South Wales, and South Australia. The majority had learned Spanish later in life when at university although three grew up in Spanish speaking countries - Spain and El Salvador. Those who hadn't, all spoke of extensive time spent abroad in Mexico, Argentina, or Spain. In addition, I did not specifically collect information about the specific types of Spanish classes or year levels SWLTs as I was curious to see if this came up in conversation as something relevant to response-able Spanish languaging or not. It certainly did, and many mentioned their experience teaching all year levels in high school (in Australia this is year 7-12) in under the state curriculum before it turned into a national curriculum and three also noted teaching Spanish Ab Initio as part of the International Baccalaureate. Three also had experience teaching in Spanish immersion programs. Five teachers taught in public schools and four in private schools.

Many participated in the interviews with children in the background suggesting that this method may also afford further flexibility especially needed when conducting research in 
a majority female profession where many participants may be engaged in childcare. After a short discussion of their ability to scroll through their timeline and stop or skip posts they wanted to narrate, I also asked them not to mention the names, posts or comments shared by others for privacy reasons. I also did not record screens, but audio only for privacy reasons. Additionally, I chose not to record screens due to the risk of capturing private data about nonresearch participants and the impracticality of redacting this information. For example, many posts contained names and personal information of Facebook friends of the participants who had not given consent to take part in the project. At times, this meant posts that SWLTs may have deemed relevant were not included in the research as they were created and shared on the SWLTs Facebook timeline by someone else. However, this was rare and did not interrupt the flow of the conversation. Most times, SWLTs were able to find another post illustrating the point they wished to highlight from another user's post in something they had posted also. I discuss further ethical considerations that emerged as I spoke with SWLTs at the end of the chapter.

The SWLTs were excited and enthusiastic to begin after our brief introduction. I had explained that they were free to narrate any post they thought was relevant to response-able Spanish languaging whether or not the connection was immediately obvious. I would also ask SWLTS to pause on posts I thought might be relevant. Some SWLTs were on desktops, and others on mobile phones. Some had kids running around in the background while others hid in quiet places. Some scrolled linearly, and only made it back to 2019 whereas others jumped between years using the menu bar at the top of the page (See Figure 1); some played the videos embedded on their pages and others took detours into stories about school, life and travels not mentioned on their Facebook timeline but prompted by a post, comment, or photo. Others sang along to music videos they had shared. I was also struck by their confidence in veering off course from my planned question which has asked "Can you talk to me about any Heinrichs, D. H. (2021) The generative effects of social media scroll-back interviews: In conversation with Spanish as a world language educators during COVID-19 in Australia. In J. Chen (Ed.), Emergency remote teaching. Springer. 
examples of response-able Spanish languaging on your Facebook timeline?”. Before beginning the interviews, I spend time taking the SWLTs through a pre-prepared PowerPoint detailing the terms response-able and languaging making sure to check they understood that they could discuss more than their moral obligations and language/semiotic resources beyond Spanish. Out of the respect for the professionalism and intelligence of the SWLTS, I did not use layman's terms nor change the terminology here and instead engaged in conversation, invited questions, and broke down the terms with them before beginning the interview. The creativity of SWLTs responses was sparked by the posts resulting in a vast array of alternative data. Whilst I could have read and analysed the similarities in the language given this is a project in language education, I was struck by the differences in their responses particularly those that highlighted issues concerning ER WLE which is a topic I had not initially intended to explore but that arose from the politically motivated and situated posts due to conducting research during this time.

Having transcribed our conversations from the scroll-back interviews, I now present the findings from a diffracting analysis using individual examples that highlight what affects are generated by virtue of this method itself and in relation to ER . Firstly, I discuss the ways in which wonder generates interruptions to the agency of myself and SWLTs in this project as an example of how scroll-back method might affect the data highlighted in ER WLE research. I then explore the ways in which the various phenomena continue to interrupt agency with a particular focus on the agency of avoidance with an example pertinent to ER WLE by looking at hesitation as data. Finally, I elaborate on an example the ethical questions raise when researchers spot issues of interest, be they avoidance or shame, and offer some thoughts on how entangling ourselves with these uncomfortable affects generated by social media in ER WLE could help us (re)imagine response-able research practices. 


\section{Generative affects emerging from/with/through social media scroll-back interviews: troubles for ER WLE}

\subsection{Wondrous interruptions of agency}

Considering my final research question asking: IN what ways might WLE respond to ER WLE research with social media, I was initially drawn to the ways in which agency was interrupted in the interviews. While the control of the scrolling offered SWLTs "socioculturally mediated capacity to act" (Ahearn, 2001) emphasising their agency as participants and reducing mine as the researcher, my own wonder about the skipped over posts generated an interruption to this traditional notion of agency. The SWLTs scrolling-on and past particular posts sparked my interest and interrupted our focus on the initial research topic and search for themes. In one instance, I interrupted Flor's scrolling and asked her to explain the reasons behind sharing specific posts on climate issue and refugees (see Figure 2 and Figure 3). Instead of discussing response-able Spanish languaging explicitly, my curiosity-fuelled interruption encouraged Flor to describe her passion for climate related issues emerging from Central America and her personal and family history as a refugee from the region, thereby, (re)interrupting the direction of the research itself. Flor's narrations of these posts emphasise the situated, entangled, and complex personal socio-political histories underpinning SWLTs languaging practices, different to the personal/professional binaries which often encourage SWLTs to separate their subjective positionings from objective pedagogical requirements. Despite, or perhaps even because of, the professional push for objectivity, during our conversation drawing on her Facebook posts Flor acknowledged that she "kind of put this out there to just, you know, throw it in their faces, really". I cautiously pondered whether my own interruption of Flor's scrolling spurred by my curiosity in posts blurring the personal/professional divide might be an example of what Maclure (2013) 
considers the "wonder that resides and radiates in data" (p.228), and that "is relational...and never completed within our control” (p.229).

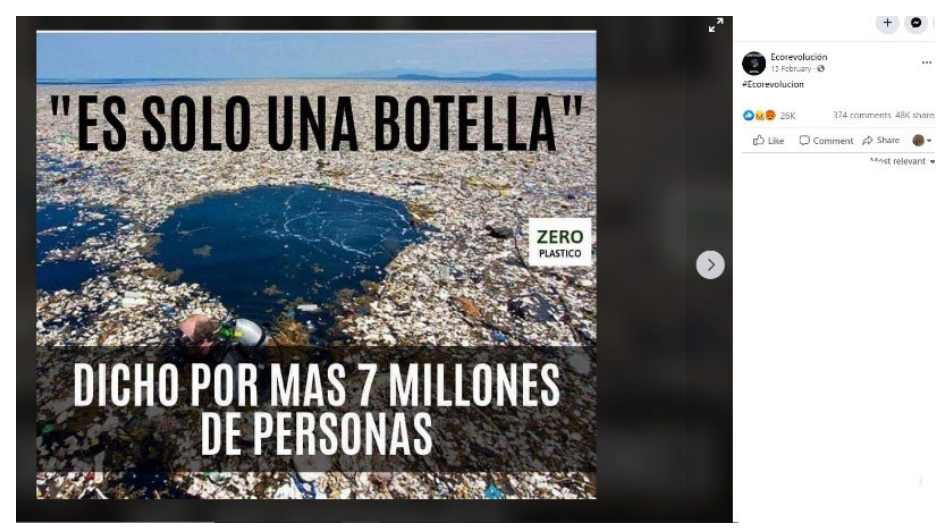

Figure 3 Illustrative screenshot of a Facebook post about refugee issues during the pandemic shared by Flor, SWLT (BRASS - Brisbane Refugee and Asylum Seeker Support Network, 2020)

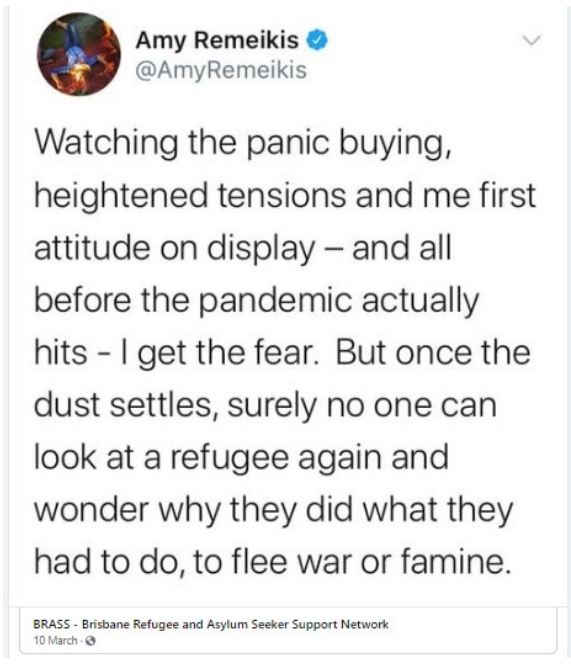

Figure 2 Illustrative screenshot of climate issue Facebook post shared by Flor, SWLT

(Evorevolución, 2020)

The generative effects of interruption and (re)interruption emerging from Flor's embodied scrolling and storying as well as my own wonder counter many of the conventional discourses in WLE research that separate the agency of the researcher/ed, the human/nonhuman, the social/scientific and the personal/professional. I refer to this using the adjectival form of wonder - wonderous - interruption of agency to highlight the entangled ways in as a world language educators during COVID-19 in Australia. In J. Chen (Ed.), Emergency remote teaching. Springer. 
which wonder inspires further wondering that is extraordinary in that we are moved beyond the ordinary research practices dictating teleology and objective data. Furthermore, this conceptualisation of agency embraces the ways in which social media scroll-back interviews entangle the human (researcher/ed) and non-human (wonder, technology) generate on-going agential intra-actions (Barad, 2007). Hence, the wonderous interruption and (re)interruption of scrolling posts and the research topic blur the boundaries of individual agency. On account of this, our conversation seems to acknowledge "the specificity of material entanglements in their agential becoming" (Barad, 2007, p. 72) performed in the context of social media research responding to a global pandemic.

\subsection{Agency of avoidance}

Even with (re)configured, entangled agency in our conversations, SWLTs and their Facebooks timelines transgressed from my planned research focus on response-able Spanish languaging practices in unexpected ways. This suggested a particular way in which WLEs might respond to ER WLE research with social media. Whilst scrolling through her timeline, Ron spotted a post of a sunset photo she had taken (see Figure 4) and then captioned. She comments "This one is about school, but there's no Spanish there either" before scrolling again and effectively avoiding any further discussion. In response to her attempt to avoid this post, I hastily responded with "Although I guess you've mentioned the online teaching there and how has that..." tentatively prompting Ron to go into more detail. My vague/imprecise comment stemmed from my hesitation to highlight a post that seemed off-topic and potentially off-limits. Ron's hasty response seemed to feed off my hesitation further as we 
only briefly diverted from the research topic as she described her affective response to moving teaching and learning online.

Ron: That was after the day one of the term. And I was just like my head was ready to explode, and I'd been crazy, and I'd gone for a run. That was my sunset. And I just shared it saying I made a bit softer. Sorry, after week one.

Danielle: Yeah. Was that week one this - this term?

Ron: Yeah. Where it was full online, no students at all. None in my classroom. And just yeah, that was sort of just seeing crisis mode like, the end of term one. This was, you know, after the first week of adaptation into remote learning and teaching.

Figure 4 Illustrative post of sunset photo post from Ron (Twelve Feet Wanderers, 2020)

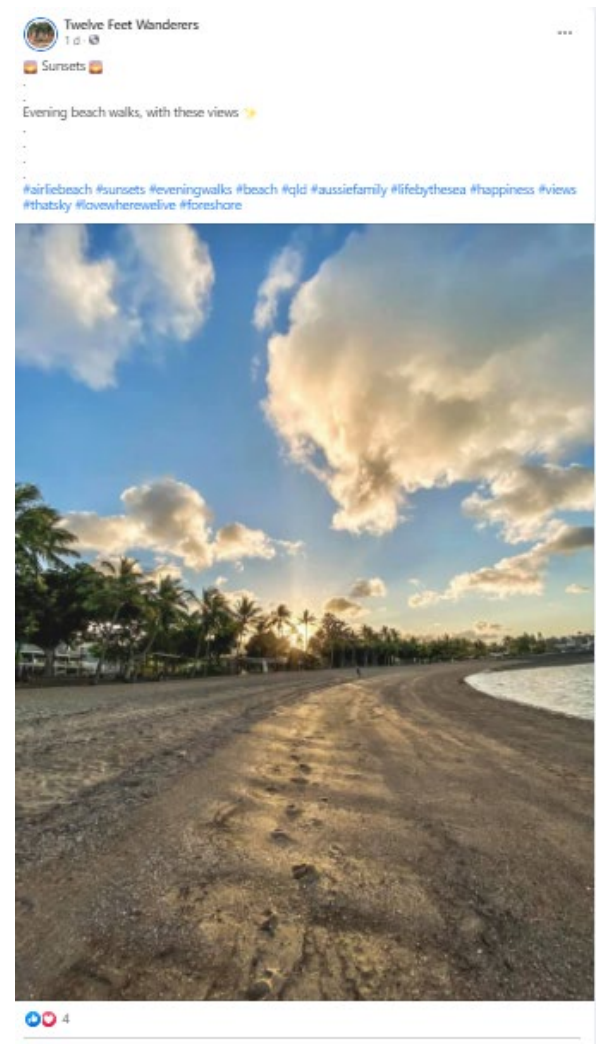

Heinrichs, D. H. (2021) The generative effects of social media scroll-back interviews: In conversation with Spanish as a world language educators during COVID-19 in Australia. In J. Chen (Ed.), Emergency remote teaching. Springer. 
The hesitation generated by Ron's attempted avoidance of a Facebook post she had likely forgotten about containing an emotional response to ER WLE but that put itself in our conversation reminded me of the ways in which a researcher hesitating to interpret such performativity "can open up surprisingly fruitful research spaces/possibilities" (Benozzo \& Gherardi, 2019, p. 153). Ron's attempted avoidance also raises further questions about agency when the non-human (technology) intercepts our conversation with saved memories perhaps meant to be kept hidden, opening up the possibility for the researcher to draw these into the research. This concern is necessary for considering the ways in which we as WLE researchers are response-able for bringing context (COVID-19, ER WLE) into conversation whilst respecting the privacy of the SWLTs we might work with.

\subsection{Shame-interest}

A final reminder of some of the ways in which WLEs might respond to ER WLE research with social media emerged in relation to shame-interest. This is also a further reminder of our response-abilities as WLE researchers that generated from my conversation with Rosalía (SWLT) about the emergency switch to online teaching and learning via Zoom:

“even I hit the ceiling and there probably... here with me hitting the ceiling, because they did - they - I got to a post where I think I said "I'm looking at quitting" because I got so cranky that they kept on - the Department of Education. Every second day I'd go in and they have changed the settings on my Zoom so that I couldn't, you know, I couldn't record all of a sudden, or I couldn't get kids - kids couldn't log on because they needed to have their department email to log on. So, it's all to protect us, I get it. But it was like, you know, teachers aren't allowed to be on a Zoom with only one student. And I'm like, 
"Well, I've only got 16 in my year ten Spanish class and, you know, there's always going to be one of them who turns up before the others"

This particular complaint of Rosalía's is important for a number of reasons; first due to the way in which she included an account of her emotive response to COVID-19 ER WLE. In doing so, she turns to matters of affect in educational research that may "disrupt patterns of disadvantage" (Mayes \& Wolfe, 2018, p. 1) such as those departmental regulations that doubt the professionalism of SWLTs when attempting to work on-on-one with their students in ER WLE situations. This suspicion of SWLTs' lack the professional capacity to work safely with their students in ER WLE scenarios further unsettles my research topic exploring responseable languaging practices. On the one hand, this example showcases the ways in which SWLTs hands are tied during ER WLE as they are legally shamed for being alone with students online. On the other hand, it raises questions about the types of emotional affects generated by EL WLE research and whether or not I as a research should "attempt to write shame as something of interest" as it "opens up the researcher to questions about whether she has breached ethical codes", thus, shaming me (Mayes \& Wolfe, 2018, p. 3). However, (re)turning to Barad's (2007) notion of diffracting, I can see the potential for my interest in writing shame not as shameful but rather an opportunity for reconfiguring connection by generating an alternative ethics of ER WLE research. Rosalía's example can be seen as having the potential to disrupt the idea that the SWLTs shame is separate from mine my as the researcher, therefore, highlighting our co-constitutive affective states generated by our mutual interest and shame.

\section{Conclusion}

My attempt of diffracting the data generated from social media scroll-back interviews with SWLTs during COVID-19 points to some possible ways in which ER WLE research can be

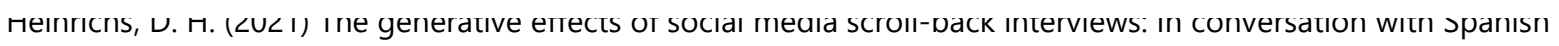
as a world language educators during COVID-19 in Australia. In J. Chen (Ed.), Emergency remote teaching. Springer. 
thought about and done differently in order to move beyond repetitive explorations of sameness whilst also offering an option for conducting research during lockdowns and other emergency situations that may limit access to school sites. In seeking out alternative or transgressive data rather than language and/or linguistic data, as might be expected in a project in WLE research, led to unexpected and surprising affects being generated. I came to realise that by diffracting rather than coding or thematically analysing my data, I could engage with more-than-language, but that this might also require more-than-human phenomena as part of the research project. By working with the difficulties of ER WLE, I was able to rescope the project in order to do this and explore some small examples of the generative affects of doing so. Most notable, I became keenly aware of the ways in which agency was entangled with researchers/participants and technology in ways that encouraged and disrupted the ability to avoid and engage with uncomfortable affects such as shame and hesitation generated by scrolling through a Facebook timeline together. I remain encouraged to undertake further research into how social media scroll-back method and diffractive analyses could open up qualitative research in ER WLE and see particular potential in the areas of pre-service and in-service teacher professional development and critical reflection where such an approach could be (re)imagined as a day-to-day tool for bridging the personal/professional, social-scientific and more.

\section{Food for thought}

- The ethics of conducting online research in WLE using social media scroll-back method extend beyond questions of privacy and anonymity. The entanglement of technology, in this case Facebook timelines, in the research also generates interest on the part of the researcher in posts which SWLTs here may have highlighted shame or that they may have wished to avoid or. As a result, researchers in this space also need 
to consider their response-abilities to respond their own interest in affects of avoidance and/or shame.

- Given the potential for social media scroll-back method to focus on more-thanlanguage data, it has the potential to be applied in a vast array of disciplines beyond WLE and in relation to a broad array of topics. However, one consideration is the fact that not all participants are comfortable sharing their social media in potentially public research and others may not have/use a social media account. In the case participants are not comfortable sharing their own personal account, there is scope to incorporate public accounts of government organisations or similar for them to narrate depending on the research focus or narrate the page of another educator - ethics permitting. These options could also work for those who do not have/use a social media page.

- In regard to future research, there seems to be significant potential for WLEs and educators in other disciplines to make use of social media scroll-back method as part of their reflective practice in novel ways. For instance, the more-than-linguistic data which may emerge through transemiotic posts as well as the affective responses to these posts provide opportunities for alternative analyses such as a diffractive analysis in the current project.

\section{Acknowledgements}

I wish to thank A/Professor Liz MacKinlay and Dr Adriana Díaz for their support in developing this methodology. I also wish to express my sincerest gratitude to the SWLTs who so enthusiastically worked with me in this project. This research was supported by an Australian Government Research Training Program Scholarship. 


\section{References}

Ahearn, L. M. (2001). Language and agency. Annual Review of Anthropology, 30(1), 109137. https://doi.org/10.1146/annurev.anthro.30.1.109

Ahmed, S. (2014). Conclusion just emotions. In The Cultural Politics of Emotion $2^{\text {nd }}$ ed., pp. 191-203). Edinburgh University Press. https://doi.org/10.3366/j.ctt1g09x4q.14

Arnold, J. (2019). The importance of affect in language learning. Neofilolog, 52, 11-14. https://doi.org/10.14746/n.2019.52.1.2

Australian Government Department of Foreign Affairs and Trade. (2018). Education in emergencies. https://www.dfat.gov.au/sites/default/files/foundation-education-inemergencies.pdf

Barad, K. (2003). Posthumanist performativity: Toward an understanding of how matter comes to matter. Signs, 28(3), 801-831. https://doi.org/10.1086/345321

Barad, K. (2007). Meeting the universe halfway quantum physics and the entanglement of matter and meaning. Duke University Press. https://doi.org/10.1215/9780822388128

Benozzo, A., \& Gherardi, S. (2019). Working within the shadow: what do we do with "notyet" data? Qualitative Research in Organizations and Management: An International Journal. https://doi.org/10.1108/QROM-09-2018-1684

Besnier, N. (1990). Language and affect. Annual Review of Anthropology, 19(1), 419-451.

\section{https://doi.org/10.1146/annurev.an.19.100190.002223}

Bozalek, V., \& Zembylas, M. (2017). Diffraction or reflection? Sketching the contours of two methodologies in educational research. International Journal of Qualitative Studies in Education (QSE), 30(2), 111-127. https://doi.org/10.1080/09518398.2016.1201166

BRASS - Brisbane Refugee and Asylum Seeker Support Network. (2020). [Image attched] [ Status update].

Heinrichs, D. H. (2021) The generative effects of social media scroll-back interviews: In conversation with Spanish as a world language educators during COVID-19 in Australia. In J. Chen (Ed.), Emergency remote teaching. Springer. 
https://www.facebook.com/brassnetwork/photos/a.676105779096247/379300454407

$\underline{3006}$

Carpenter, J. P., \& Harvey, S. (2020). Perceived benefits and challenges of physical educators' use of social media for professional development and learning. Journal of Teaching in Physical Education, 1, 1-11.

https://doi.org/https://doi.org/10.1123/jtpe.2020-0002

Carpenter, J. P., \& Krutka, D. G. (2015). Engagement through microblogging: educator professional development via Twitter. Professional Development in Education, 41(4), 707-728. https://doi.org/10.1080/19415257.2014.939294

Clayton, K., Blair, S., Busam, J. A., Forstner, S., Glance, J., Green, G., Kawata, A., Kovvuri, A., Martin, J., Morgan, E., Sandhu, M., Sang, R., Scholz-Bright, R., Welch, A. T., Wolff, A. G., Zhou, A., \& Nyhan, B. (2019). Real solutions for fake news? Measuring the effectiveness of general warnings and fact-check tags in reducing belief in false stories on social media. Political Behavior. https://doi.org/10.1007/s11109-019$\underline{09533-0}$

Dolphijn, R., \& Tuin, I. v. d. (2012). New materialism: Interviews \& cartographies. Open Humanities Press. https://doi.org/10.3998/ohp.11515701.0001.001

Dubois, E., Minaeian, S., Paquet-Labelle, A., \& Beaudry, S. (2020). Who to trust on social media: How opinion leaders and seekers avoid disinformation and echo chambers. Social Media + Society, 6(2), 2056305120913993. https://doi.org/10.1177/2056305120913993

Evorevolución. (2020, February 15). \#Evorevolución [Image attached] [Status update]. Facebook.

https://www.facebook.com/ecorevolucionoficial/photos/a.1784076738490518/267976 $\underline{6095588240 /}$

Heinrichs, D. H. (2021) The generative effects of social media scroll-back interviews: In conversation with Spanish as a world language educators during COVID-19 in Australia. In J. Chen (Ed.), Emergency remote teaching. Springer. 
Galvin, S., \& Greenhow, C. (2020). Writing on social media: A review of research in the high school classroom. TechTrends, 64(1), 57-69. https://doi.org/10.1007/s11528-019$\underline{00428-9}$

García, O., \& Wei, L. (2013). Translanguaging: Language, bilingualism and education (Vol. 63). Palgrave Macmillan. https://doi.org/10.1057/9781137385765

Greenhow, C., \& Chapman, A. (2020). Social distancing meet social media: digital tools for connecting students, teachers, and citizens in an emergency. Information and learning science, 121(5/6), 341-352. https://doi.org/10.1108/ILS-04-2020-0134

Haraway, D. J. (2016). Staying with the trouble: making kin in the Chthulucene. Duke University Press. https://doi.org/10.1215/9780822373780

Heinrichs, D. H. (2020). Decoloniality, Spanish and Latin American studies in Australian universities: ¿es un mundo ch'ixi posible? Third World Thematics: A TWQ Journal, 5(01). https://doi.org/10.1080/23802014.2020.1798277

Hodges, C., Moore, S., Lockee, B., Trust, T., \& Bond, A. (2020). The difference between emergency remote teaching and online learning. Educause Review, 27. https://medicine.hofstra.edu/pdf/faculty/facdev/facdev-article.pdf

Hootsuite. (2020). Digital 2020 July Global Statshot Report. https://hootsuite.com/pages/digital-2020

Kamberelis, G., Dimitriadis, G., \& Welker, A. (2018). Focus group research and/in figured worlds. In The SAGE handbook of qualitative research (5th ed., pp. 692-716). Sage.

Kasparek, N., \& Turner, M. W. (2020). Puzzling about special educational needs in EFL teacher development: A duoethnographic inquiry. In R. J. Lowe \& L. Lawrence (Eds.), Duoethnography in English language teaching: Research, reflection and classroom application. Multilingual Matters.

\section{https://doi.org/10.21832/9781788927192}

Heinrichs, D. H. (2021) The generative effects of social media scroll-back interviews: In conversation with Spanish as a world language educators during COVID-19 in Australia. In J. Chen (Ed.), Emergency remote teaching. Springer. 
King, K. A., Lai, Y., \& May, S. (2017). Research Methods in Language and Education (3rd ed.). Springer International Publishing. https://doi.org/10.1007/978-3-319-02249-9

Lee, J. S., \& Chen Hsieh, J. (2019). Affective variables and willingness to communicate of EFL learners in in-class, out-of-class, and digital contexts. System, 82, 63-73. https://doi.org/https://doi.org/10.1016/j.system.2019.03.002

Maal, M., \& Wilson-North, M. (2019). Social media in crisis communication - the "do's" and “don'ts”. International Journal of Disaster Resilience in the Built Environment, 10(5), 379-391. https://doi.org/10.1108/IJDRBE-06-2014-0044

MacLure, M. (2013). The wonder of data. Cultural Studies $\leftrightarrow$ Critical Methodologies, 13(4), 228-232. https://doi.org/10.1177/1532708613487863

Malecki, K. M. C., Keating, J. A., \& Safdar, N. (2020). Crisis communication and public perception of COVID-19 risk in the era of social media. Clinical Infectious Diseases. https://doi.org/10.1093/cid/ciaa758

Manca, S. (2020). Snapping, pinning, liking or texting: Investigating social media in higher education beyond Facebook. The Internet and Higher Education, 44, 100707. https://doi.org/https://doi.org/10.1016/j.iheduc.2019.100707

Mayes, E., \& Wolfe, M. (2018). Shameful interest in educational research. Critical Studies in Education, 1-17. https://doi.org/10.1080/17508487.2018.1489871

O' Brien, S., \& Federici, F. M. (2019). Crisis translation: considering language needs in multilingual disaster settings. Disaster Prevention and Management: An International Journal, 29(2), 129-143. https://doi.org/10.1108/DPM-11-2018-0373

Oeldorf-Hirsch, A., Schmierbach, M., Appelman, A., \& Boyle, M. P. (2020). The ineffectiveness of fact-checking labels on news memes and articles. Mass Communication and Society, 23(5), 682-704.

\section{https://doi.org/10.1080/15205436.2020.1733613}

Heinrichs, D. H. (2021) The generative effects of social media scroll-back interviews: In conversation with Spanish as a world language educators during COVID-19 in Australia. In J. Chen (Ed.), Emergency remote teaching. Springer. 
Paul, J. Z., \& Friginal, E. (2019). The effects of symmetric and asymmetric social networks on second language communication. Computer Assisted Language Learning, 32(5-6), 587-618. https://doi.org/10.1080/09588221.2018.1527364

Peeters, W. (2019). The peer interaction process on Facebook: a social network analysis of learners' online conversations. Education and Information Technologies, 24(5), 31773204. https://doi.org/10.1007/s10639-019-09914-2

Pescaroli, G., \& Alexander, D. (2015). A definition of cascading disasters and cascading effects: Going beyond the "toppling dominos” metaphor. Planet@Risk,3(1), 58-67. http://citeseerx.ist.psu.edu/viewdoc/download?doi=10.1.1.874.4335\&rep=rep1\&type= $\underline{\mathrm{pdf}}$

Queensland Government. (2020). Research services. https://education.qld.gov.au/aboutus/reporting-data-research/research

Reinders, H., \& Wattana, S. (2014). Affect and willingness to communicate in digital gamebased learning. ReCall, 27. https://doi.org/10.1017/S0958344014000226

Riley, D. (2005). Impersonal passion: Language as affect. Duke University Press. https://doi.org/10.1215/9780822386780

Robards, B., \& Lincoln, S. (2019). Social media scroll back method. In Sage research methods: Foundations.

https://methods.sagepub.com/base/download/FoundationEntry/social-media-scrollback-method

Sirivedin, P., Soopunyo, W., Srisuantang, S., \& Wongsothorn, A. (2018). Effects of Facebook usage on English learning behavior of Thai English teachers. Kasetsart Journal of Social Sciences, 39(2), 183-189.

https://doi.org/https://doi.org/10.1016/j.kjss.2018.03.007

Heinrichs, D. H. (2021) The generative effects of social media scroll-back interviews: In conversation with Spanish as a world language educators during COVID-19 in Australia. In J. Chen (Ed.), Emergency remote teaching. Springer. 
Solmaz, O. (2017). Autonomous language learning on Twitter: Performing affiliation with target language users through\# hashtags. Journal of Language and Linguistic Studies, 13(2), 204-220. https"//www.jlls.org

Statista. (2020). Number of monthly active Facebook users worldwide as of 2 nd quarter 2020 (in millions). https://www.statista.com/statistics/264810/number-of-monthly-activefacebook-users-worldwide/

Tananuraksakul, N. (2015). An investigation into the impact of Facebook group usage on students' affect in language learning in a Thai context. International Journal of Teaching and Learning in Higher Education, 27(2), 235-246.

Taskiran, A., Gumusoglu, E. K., \& Aydin, B. (2018). Fostering foreign language learning with Twitter: Reflections from English learners. Turkish Online Journal of Distance Education, 19(1), 100-116. https://eric.ed.gov/?id=EJ1165854

Twelve Feet Wanderers. (2020). [Image attached] [Status update]. Facebook. https://www.facebook.com/twelvefeetwanderers/posts/140206571135732

The right to education in emergency situations : resolution, (2010). https://digitallibrary.un.org/record/685964? $\ln =\mathrm{en}$

United Nations. (2019). Education in emergencies. https://en.unesco.org/themes/education$\underline{\text { emergencies }}$

Villafuerte, J., \& Romero, A. (2017). Learners' attitudes toward foreign language practice on Social Network Sites. Journal of Education and Learning, 6(4), 145-158. https://doi.org/10.5539/jel.v6n4p145

Warriner, D. S. (2012). When the macro facilitates the micro: A study of regimentation and emergence in spoken interaction. Anthropology \& education quarterly, 43(2), 173191. https://doi.org/10.1111/j.1548-1492.2012.01168.x

Heinrichs, D. H. (2021) The generative effects of social media scroll-back interviews: In conversation with Spanish as a world language educators during COVID-19 in Australia. In J. Chen (Ed.), Emergency remote teaching. Springer. 
Weldon, P., McMillan, J., Rowley, G., \& McKenzie, P. (2014). Profiles of teachers in selected curriculum areas: Further analyses of the Staff in Australia's Schools 2013 Survey. https://docs.education.gov.au/system/files/doc/other/sias_2013 supplementary report. $\underline{\mathrm{pdf}}$

Wu, Y., \& Lin, A. M. (2019). Translanguaging and trans-semiotising in a CLIL biology class in Hong Kong: Whole-body sense-making in the flow of knowledge co-making. Classroom Discourse, 10(3-4), 252-273.

Xie, Y., Qiao, R., Shao, G., \& Chen, H. (2017). Research on Chinese social media users' communication behaviors during public emergency events. Telematics and Informatics, 34(3), 740-754. https://doi.org/https://doi.org/10.1016/j.tele.2016.05.023

Xu, J. (2020). Does the medium matter? A meta-analysis on using social media vs. traditional media in crisis communication. Public Relations Review, 46(4), 101947. https://doi.org/https://doi.org/10.1016/j.pubrev.2020.101947

Xue, S., \& Churchill, D. (2020). Educational affordances of mobile social media for language teaching and learning: a chinese teacher's perspective. Computer Assisted Language Learning, 1-30. https://doi.org/10.1080/09588221.2020.1765811

Heinrichs, D. H. (2021) The generative effects of social media scroll-back interviews: In conversation with Spanish as a world language educators during COVID-19 in Australia. In J. Chen (Ed.), Emergency remote teaching. Springer. 